\title{
A Study on the Design Method for the Material Composition of Small Particle-Size Asphalt Mixture for Controlling Cracks in Asphalt Pavement
}

\author{
Jiyu Xin ${ }^{1,2}{ }^{\oplus}$, Jianzhong Pei ${ }^{1, *}$, Mitsuyoshi Akiyama ${ }^{2, *} \mathbb{C}$, Rui Li ${ }^{1}{ }^{\oplus}$, Jiupeng Zhang ${ }^{1}$ and \\ Libo Shao ${ }^{3}$ \\ 1 School of Highway, Chang'an University, Xi'an 710064, China; xinjiyu@chd.edu.cn (J.X.); \\ lirui@chd.edu.cn (R.L.); zhjiupeng@chd.edu.cn (J.Z.) \\ 2 Department of Civil and Environmental Engineering, Waseda University, Tokyo 169-8555, Japan \\ 3 Jinan Jinqu Road Survey Design Research Co., Ltd., Jinan 250014, China; shaolibo37@163.com \\ * Correspondence: peijianzhong@126.com (J.P.); akiyama617@waseda.jp (M.A.)
}

Received: 5 March 2019; Accepted: 8 May 2019; Published: 15 May 2019

Featured Application: Authors are encouraged to provide a concise description of the specific application or a potential application of the work. This section is not mandatory.

\begin{abstract}
Generally, various kinds of cracks are the main type of distresses during the service period of asphalt pavements. To save maintenance costs and improve the crack resistance of asphalt pavements effectively, this paper presents a unique design method for the material composition of small particle-size (SPS) asphalt mixture for controlling cracks in asphalt pavement. First, Stone Mastic Asphalt (SMA)-II was designed as a basic gradation according to the A.N. Talbot curve and SMA-II-1, SMA-II-2 and SMA-II-3 were designed according to the Superpave mix design method, the Bailey method and the Particle interference theory, respectively. Second, based on Marshall test results, the optimal fiber content and optimal asphalt content of three gradations were determined. Then, the influence of the passing rate of $1.18-\mathrm{mm}$ sieve and $0.075-\mathrm{mm}$ sieve on the air voids of SMA-II and the influence of the filler-asphalt ratio on the performance of SMA-II were investigated, and an appropriate range of filler-asphalt ratio was obtained. Finally, a high-temperature performance test, a water stability test, and a skid resistance test demonstrate that the overall performance of SMA-II can satisfy the specifications. A low-temperature bend test and analysis of bending strain energy density show that SMA-II with a crumb rubber modifier and a polymer fiber has better crack resistance performance than SMA-I (SBS-modified mixture). Life-cycle cost analysis shows the economic advantage of SPS asphalt thin overlays over traditional AC-13 thin overlays.
\end{abstract}

Keywords: small particle-size (SPS) asphalt mixture; crumb rubber modifier; polyester fiber; cracks control; material composition; pavement performance test; life-cycle cost analysis

\section{Introduction}

Asphalt pavement is exposed directly to the environment and continuous temperature cycling, and the sharp drop in temperature can cause huge shrinkage stress. Because it is closely bonded with the base, the asphalt surface will not be free to bend, which, as a result, can create different stress at the surface and the bottom of the asphalt surface layer. Combined with other stresses, larger tensile stress and cracks will appear in the surface. Under the repeated action of traffic loads and temperature stresses, micro-cracks in the surface and base will expand, densify and connect to eventually form macro-cracks, then cause damage to the pavement structure [1-3]. Thus, to control the road surface 
cracks, effective preventive maintenance measures are necessary. Hot mix asphalt (HMA) thin overlay technology, as a preventive maintenance method, has been widely used around the world.

In the 1970s, France was the first country to use a thin asphalt overlay called Béton Bitumineux Mince (BBM) on high-graded asphalt pavement [4]. In the early 1990s, the United Kingdom began to construct ultra-thin asphalt concrete (VTHMAL) test roads [5]. The United States introduced and promoted Stone Mastic Asphalt (SMA) technology in 1991. NovaChip is a pavement maintenance treatment developed by the Colas USA company [6]. In 1998, Wroclaw in Poland built a thin overlay test road, which, after being in service for several years, still has good performance. Stockholm in Sweden paved an ultra-thin asphalt concrete test road in 1999 [5]. Indonesia developed an ultra-thin overlay (20-40 mm) called LASTIKA, a hot mix asphalt concrete overlay with Superflex modified asphalt [7]. Gradually, a fine-grained SMA mixture, the nominal maximum particle sizes of which are $4.75 \mathrm{~mm}$ and $9.5 \mathrm{~mm}$, were developed for the preventive maintenance of high-grade highway [8]. Application experience shows that thin asphalt overlay is an effective technology for delaying pavement distresses, restoring pavement function, improving pavement service level and extending the service life of the pavement $[9,10]$. For example, some research has demonstrated that thin overlays can efficiently improve the skid resistance of pavements [11-15]. Besides, asphalt overlays can also delay and restore various kinds of cracks in asphalt pavements. Some researchers tried to improve the crack resistance of asphalt mixture by developing new materials. For example, Wang et al. studied the resistance to reflective cracks of interlayer materials in asphalt overlay; the test results showed that Atactic Polypropylene (APP) asphalt felt $>$ Fiberglass geogrid $>$ Geotextile $>$ Without interlayer material [16]. Fallah et al. investigated the effects of grid stiffness, tensile strength, coating type, amount of tack coat, overlay thickness, crack width, and stiffnesses of asphalt overlay and existing asphalt concrete on reinforced asphalt overlay performance with a geogrid interlayer [17]. V. Vinay Kumar et al. used a kind of geosynthetic called glass-grid composite (GGC) to improve the crack resistance of asphalt overlays because GGC can mobilize high tensile strength at a low strain value [18]. Some researchers tried to improve crack resistance with material composition. For example, Zhang et al. analyzed the effect of notch depth, gradation, asphalt properties and temperature on the crack resistance of the asphalt mixture based on semicircular bending (SCB) tests [19]. Liu et al. studied the effects of nominal maximum aggregate size (NMAS) on the performance of SMA and found that a decrease of NMAS showed better cracking and raveling resistance [20]. Garcia-Gil et al. studied the effect of aggregate gradation on the cracking performance of asphalt concrete for thin overlays and the results showed there is a significant correlation between the fine fraction content and the maximum nominal aggregate size and the cracking performance of the asphalt concrete mixtures [21]. In general, amongst research about the material composition and performance of SMA, research on gradations whose nominal maximum size of aggregate is $4.75 \mathrm{~mm}$ (dense-graded) is still rare. Still, in the current mix design of small-particle size asphalt mixture, high-temperature performance and water stability were used to evaluate the performance of asphalt mixture. Thus, more investigations including material composition and anti-crack performance are therefore needed to establish a systematic study on small-particle size (SPS) asphalt mixture.

Top-down cracks usually appear in asphalt surface layers within 5 years after construction and research showed that temperature and loads stresses under high and low temperatures are major factors. The relationship between pavement surface cracks and pavement structure is still uncertain; however, in fact, the appearance of cracks is closely related to asphalt mixture. Meanwhile, the severe oxidation of asphalt binder within a few millimeters of the pavement surface will reduce the tensile strength of the mixture, a larger tensile strain will appear in the pavement surface when the surface temperature approximates or exceeds the softening point at high temperatures. All of these are main contributors of top-down cracks [22,23]. Thus, it would be more effective to improve pavement crack resistance based on the material composition of asphalt mixture. 
The small particle-size (SPS) asphalt mixture proposed in this paper is dense-graded mixture with a high content of asphalt. The nominal maximum size of aggregate is $4.75 \mathrm{~mm}$, the proportion of aggregate passing a $2.36-\mathrm{mm}$ sieve is $70 \%$, asphalt content is between $6 \%$ and $8 \%$.

\section{Components of Asphalt Mixture}

\subsection{Crumb Rubber Modifier}

Crumb rubber modifier (CRM) can improve the high temperature resistance, anti-aging resistance and elastic properties of matrix asphalt. Engineering practice showed that rubberized asphalt concrete has obvious advantages in delaying reflective cracks, thinning asphalt pavement thickness, withstanding heavy traffic, reducing road noise and resisting adverse climate [24,25].

Due to the differences in chemical composition and strong inertia between crumb rubber and asphalt, a swelling reaction usually occurs. Then, the prepared swollen rubber particles can uniformly disperse and suspend in asphalt; as a result, the asphalt changes from a single-phase system into a two-phase system which will cause changes in the interfacial properties and pavement performance of the asphalt [26-28]. Rubberized asphalt has several advantages: First, the increase of the viscosity of modified asphalt can improve high temperature stability of asphalt mixture. Then the temperature sensitivity of the asphalt decreases after crumb rubber modification. What is more, the low-temperature ductility of the asphalt will be improved after modification. Also, the water damage resistance of the asphalt mixture will be enhanced because of the increase of the rubberized asphalt film thickness of the aggregate. Finally, driving safety will be enhanced because of the increase of friction between vehicle tires and the pavement's surface [29].

The rubberized asphalt used in this study was prepared indoors. Although the process was relatively simple, each procedure must be strictly controlled. The production procedures of rubberized asphalt are shown in Figure 1 and the Tuben test was performed to determine the tendency of CRM to separate from the asphalt binder during static storage at a controlled temperature. If the rubberized asphalt binder shows a tendency to separate during storage, some sort of agitation or stirring or reformulation of the binder must be considered. Testing was conducted in accordance with EN-13399 (Standard Practice for Determining the Separation Tendency of Polymer from Polymer-Modified Asphalt) [30].

Notes:

1. The fineness of the crumb rubber is $40 \sim 80$ meshes, the amount of crumb rubber is $20 \%$ of the matrix asphalt, the crumb rubber was dried at $110^{\circ} \mathrm{C}$.

2. The matrix asphalt is 70\# Karamay heavy traffic petroleum asphalt.

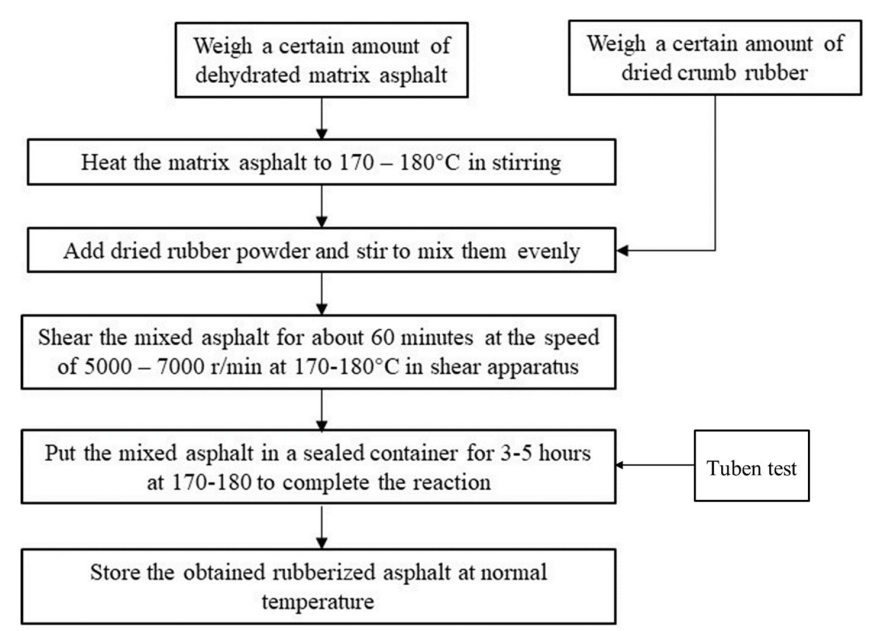

Figure 1. Preparation flow chart of rubberized asphalt. 
Table 1 shows the technical indicators of the matrix asphalt binder in this study. According to the test results in Table 2, all technical indicators of the asphalt-rubber binder can meet the Chinese specification JT/T 798-2011 [31].

Table 1. Technical indicators of matrix asphalt binder.

\begin{tabular}{|c|c|c|c|c|}
\hline Indicators & Unit & Test Result & Requirement & Test Method [32] \\
\hline Penetration $\left(25^{\circ} \mathrm{C}, 100 \mathrm{~g}, 5 \mathrm{~s}\right)$ & $0.1 \mathrm{~mm}$ & 70 & $60 \sim 80$ & T 0604-2011 \\
\hline Penetration index & - & -0.86 & $-1.5 \sim+1.0$ & Т 0604-2011 \\
\hline Ductility $\left(15^{\circ} \mathrm{C}\right)$ & $\mathrm{cm}$ & $>150$ & $\geq 100$ & T 0605-2011 \\
\hline Softening point & ${ }^{\circ} \mathrm{C}$ & 48.5 & $\geq 46$ & T 0606-2011 \\
\hline Dynamic viscosity $\left(60^{\circ} \mathrm{C}\right)$ & $\mathrm{Pa} \cdot \mathrm{s}$ & 184 & $\geq 180$ & Т 0625-2011 \\
\hline Flash point & ${ }^{\circ} \mathrm{C}$ & 332 & $\geq 260$ & T 0613-2011 \\
\hline Density $\left(15^{\circ} \mathrm{C}\right)$ & $\mathrm{g} / \mathrm{cm}^{3}$ & 1.030 & - & Т 0603-2011 \\
\hline Solubility in Trichloroethylene & $\%$ & 99.8 & $>99.5$ & Т 0607-2011 \\
\hline Wax content & $\%$ & 1.72 & 2.2 & Т 0615-2011 \\
\hline \multicolumn{5}{|c|}{ Thin-Film Oven test (TFOT) $\left(163^{\circ} \mathrm{C}, 5 \mathrm{~h}\right)$} \\
\hline Loss on heating & $\%$ wt & 0.16 & $\leq 0.8$ & T 0609-2011 \\
\hline Retained penetration after TFOT & $\%$ & 68.9 & $\geq 61$ & T 0609-2011 \\
\hline Ductility after TFOT $\left(15^{\circ} \mathrm{C}\right)$ & $\mathrm{cm}$ & 15 & $\geq 15$ & T 0605-2011 \\
\hline
\end{tabular}

Table 2. Technical indicators of asphalt-rubber binder.

\begin{tabular}{|c|c|c|c|c|}
\hline Indicators & Unit & Test Result & Requirement & Test Method \\
\hline Rotary viscosity $\left(180^{\circ} \mathrm{C}\right)$ & $\mathrm{Pa} \cdot \mathrm{s}$ & 3.2 & $1.0 \sim 4.0$ & T 0604-2011 [31] \\
\hline Penetration $\left(25^{\circ} \mathrm{C}, 100 \mathrm{~g}, 5 \mathrm{~s}\right)$ & $0.1 \mathrm{~mm}$ & 70 & $40 \sim 60$ & T 0604-2011 [32] \\
\hline Softening point & ${ }^{\circ} \mathrm{C}$ & 58.2 & $>56$ & T 0606-2011 [32] \\
\hline Elastic recovery & $\%$ & 75 & 55 & T 0662-2000 [32] \\
\hline Ductility $\left(5^{\circ} \mathrm{C}\right)$ & $\mathrm{cm}$ & 16.7 & $>10$ & Т 0605-2011 [32] \\
\hline
\end{tabular}

\subsection{Fibers}

Fibers were used to strengthen the crack resistance of small particle-size asphalt mixture [33]. The following factors should be taken into account when selecting fibers:

- the capacity of adsorbing asphalt;

- the adhesiveness with asphalt;

- the improvement on crack resistance of mixture.

Frequently-used fibers in pavement engineering included lignin fiber, polyester fiber, mineral fiber and fiberglass. Compared with others, polyester fiber has many advantages such as good chemical stability, microbe-resistant properties, acid resistance, strong anti-erosion ability for normal non-polar solvents, high intensity, moderate extensibility, high modulus and good elasticity, except poor alkali resistance [34]. Thus, TF polyester fiber produced by a company in Gansu Province was selected for this paper. The technical indicators are shown in Table 3 and the indicator values demonstrate that TF polyester fiber will be stable in the asphalt mixture during the performance tests.

Table 3. Technical indicators of polyester fiber.

\begin{tabular}{ccccc}
\hline Strength/MP & Ductility/\% & Heat Resistance $/{ }^{\circ} \mathbf{C}$ & Diameter/ $\mu \mathrm{m}$ & Dispersity \\
\hline 600 & $30 \pm 6$ & 260 & $20 \pm 5$ & Even \\
\hline
\end{tabular}




\section{Gradation Design of Aggregates}

\subsection{Gradation Design Theory}

There are two gradation theories: the maximum density curve theory and the particle interference theory. The former describes the grain size distribution of continuous gradation and is usually used in continuous gradation, while the latter is used to calculate both continuous and gap-graded gradation. Representative gradation design methods are as follows [35]:

(1) W.B. Fuller curve:

$$
P=100\left(\frac{d}{D}\right)^{0.5} \%
$$

where, $P$ is passing rate of sieve $d_{i}(\mathrm{~mm})$. $D$ is maximum grain size of mineral mixture.

(2) A.N. Talbot curve:

$$
P=100\left(\frac{d}{D}\right)^{n} \%
$$

where, $n$ is the text index. $d$ and $D$ have the same meaning with those in Equation (1)

(3) K method: Aggregate gradation curve based on mass degression coefficient $k$ of grain gradation presented by Н. Н. Иванов.

(4) The theory of particle interference presented by C.A.G. Weymouth:

$$
\Psi_{s}=\frac{\Psi_{0}}{\left(\frac{d}{D}+1\right)^{3}}
$$

where, $\Psi_{S}$ is solid volume ratio of secondary size fraction. $\Psi_{0}$ is theoretical solid volume ratio of secondary size fraction. $d$ is the grain size of former size fraction. $D$ is the grain size of secondary size fraction.

\subsection{Gradation Design of SPS Asphalt Mixture}

Goode and Lufsey found that when the gradation index is 0.5 in the Fuller curve, voids in the mineral aggregate (VMA) will be too low to meet indicators such as air voids and the saturation of asphalt mixture. In view of this, the gradation index should be 0.45 [36]. There are control points and restricted zones in Superpave aggregate gradation design as shown in Figure 2. Studies have shown that the gradation curve under the restricted zone can provide the asphalt mixture with better rutting resistance $[37,38]$.

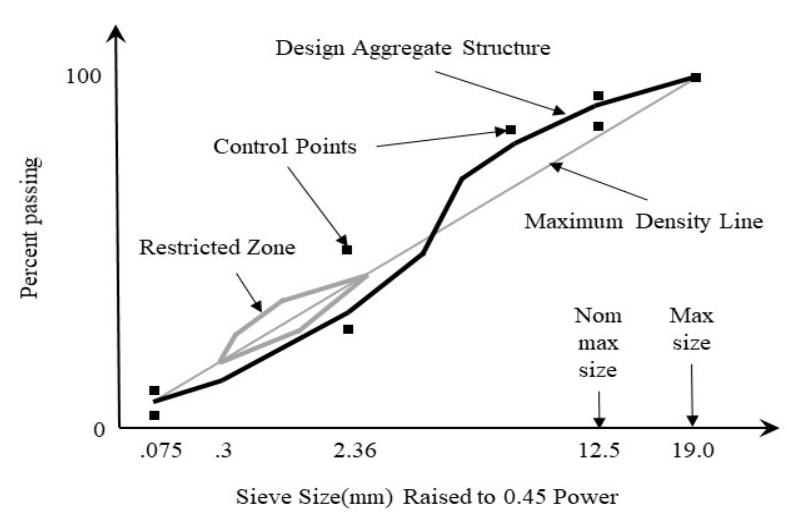

Figure 2. Superpave control points and restricted zone.

In this study, Asphalt Concrete (AC) gradation was adopted as the basis of mixture design. The technical indicators about coarse aggregate, fine aggregate and mineral filler can be seen in 
Tables A1-A3 in Appendix A. According to A.N. Talbot curve (4), the basic gradation SMA-II is shown in Table 4.

$$
P=100\left(\frac{d}{D}\right)^{n} \%
$$

where $n=0.45$, the gradation is as follows in Table 4 :

Table 4. SMA-II gradation calculation.

\begin{tabular}{ccccccccc}
\hline Grain Size/mm & $\mathbf{9 . 5}$ & $\mathbf{4 . 7 5}$ & $\mathbf{2 . 3 6}$ & $\mathbf{1 . 1 8}$ & $\mathbf{0 . 6}$ & $\mathbf{0 . 3}$ & $\mathbf{0 . 1 5}$ & $\mathbf{0 . 0 7 5}$ \\
\hline Passing rate/\% & 100 & 73.2 & 53.4 & 39.1 & 28.9 & 21.1 & 15.5 & 11.3 \\
\hline
\end{tabular}

To investigate the influence of gradation on the performance of SPS rubberized asphalt mixture, based on the original gradation SMA-II, SMA-II-1 was designed by way of the Superpave mix design method and SMA-II-2 was designed by way of the Bailey method. SMA-II-3 was designed according to particle interference theory. In contrast, SMA-I was designed as a traditional SMA- 5 to the Chinese specification JTG F40-2004 [39]. Four comparative gradations are shown in Table 5 and Figure 3.

Table 5. SMA-II gradation design.

\begin{tabular}{ccccccccc}
\hline Particle Size/mm & $\mathbf{9 . 5}$ & $\mathbf{4 . 7 5}$ & $\mathbf{2 . 3 6}$ & $\mathbf{1 . 1 8}$ & $\mathbf{0 . 6}$ & $\mathbf{0 . 3}$ & $\mathbf{0 . 1 5}$ & $\mathbf{0 . 0 7 5}$ \\
\hline Passing rate of SMA-I & 100 & 95 & 46.5 & 29 & 23 & 18.5 & 15.5 & 13.5 \\
Passing rate of SMA-II-1/\% & 100 & 76.7 & 55.6 & 36.3 & 23.3 & 18.3 & 13.5 & 9.5 \\
Passing rate of SMA-II-2/\% & 100 & 95 & 85 & 70 & 55 & 35 & 18 & 12 \\
Passing rate of SMA-II-3/\% & 100 & 88.2 & 67.6 & 47.1 & 47.1 & 29.4 & 16.5 & 10.5 \\
\hline
\end{tabular}

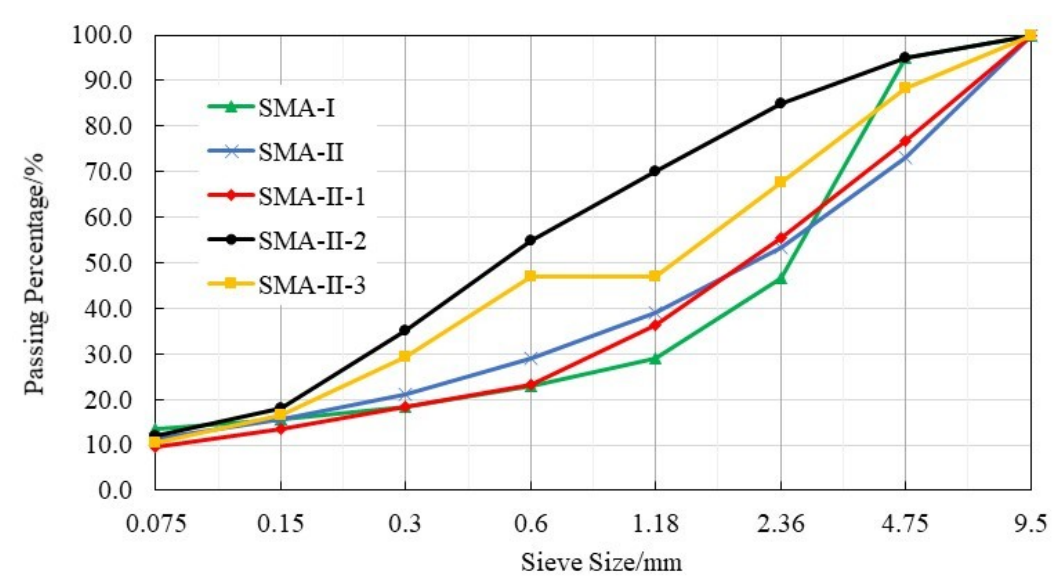

Figure 3. Gradation curves of SMA-I and SMA-II.

\section{Mix Design of SPS Asphalt Mixture}

\subsection{Determination of Optimal Fiber Content and Optimal Asphalt Content}

To determine the optimal fiber and asphalt content, the optimal composition of the asphalt mixture without fiber was first determined by the Marshall test. Then, the polymer fiber, as the admixture, was added to the asphalt mixture at a certain interval of content, while the asphalt content should increase at an appropriate proportion. Hence, under each fiber content, Marshall samples were molded respective to a certain interval of asphalt content and the optimal asphalt-aggregate ratio was determined.

Marshall test results of the mixture without fiber are shown in Tables 6-8: 
Table 6. Marshall test results of SMA-II-1.

\begin{tabular}{cccccc}
\hline Test Items & \multicolumn{5}{c}{ Test Values } \\
\hline Asphalt-aggregate ratio/\% & 5.3 & 5.8 & 6.3 & 6.8 & 7.3 \\
Bulk density/(g.cm $\left.{ }^{-3}\right)$ & 2.393 & 2.427 & 2.445 & 2.438 & 2.422 \\
VV/\% & 5.4 & 4.2 & 3.4 & 2.7 & 1.5 \\
VMA/\% & 17.3 & 17.6 & 17.6 & 19.2 & 21.5 \\
VFA/\% & 68.9 & 75.9 & 80.6 & 85.7 & 92.9 \\
Stability/kN & 10.65 & 10.94 & 11.12 & 11.02 & 10.41 \\
FL/mm & 3.31 & 3.52 & 3.85 & 4.33 & 4.65 \\
\hline
\end{tabular}

Table 7. Marshall test results of SMA-II-2.

\begin{tabular}{cccccc}
\hline Test Items & \multicolumn{5}{c}{ Test Values } \\
\hline Asphalt-aggregate ratio/\% & 7.1 & 7.6 & 8.1 & 8.6 & 9.1 \\
Bulk density/(g·cm $\left.{ }^{-3}\right)$ & 2.367 & 2.395 & 2.406 & 2.368 & 2.343 \\
VV/\% & 5.6 & 4.5 & 3.4 & 2.5 & 1.6 \\
VMA/\% & 20.1 & 19.0 & 18.6 & 20.0 & 20.2 \\
VFA/\% & 72.3 & 76.1 & 81.6 & 87.4 & 91.9 \\
Stability/kN & 9.31 & 9.82 & 10.35 & 9.91 & 9.73 \\
FL/mm & 4.22 & 4.58 & 5.15 & 5.74 & 6.13 \\
\hline
\end{tabular}

Table 8. Marshall test results of SMA-II-3.

\begin{tabular}{cccccc}
\hline Test Items & \multicolumn{5}{c}{ Test Values } \\
\hline Asphalt-aggregate ratio/\% & 6.1 & 6.6 & 7.1 & 7.6 & 8.1 \\
Bulk density/(g.cm ${ }^{-3}$ ) & 2.397 & 2.422 & 2.433 & 2.418 & 2.402 \\
VV/\% & 5.1 & 4.3 & 3.6 & 2.4 & 1.5 \\
VMA/\% & 19.2 & 18.0 & 17.3 & 18.2 & 19.7 \\
VFA/\% & 73.7 & 76.3 & 79.5 & 86.6 & 92.5 \\
Stability/kN & 9.72 & 10.51 & 10.67 & 10.26 & 9.83 \\
FL/mm & 3.37 & 3.96 & 4.33 & 4.75 & 5.35 \\
\hline
\end{tabular}

Air voids have a significant influence on the performance of the mixture and should be strictly controlled within a reasonable range. Thus, air voids in this test were decreased within the allowable range to enhance the crack resistance of the dense-graded mixture. According to specification JTG F40-2004 [39], the air voids should be between 3.5\% and $4 \%$.

According to the Marshall test results, for SMA-II-1, the stability first increases from $10.65 \mathrm{kN}$ to the maximum value of $11.12 \mathrm{kN}$ with the increase of the asphalt-aggregate ratio from $5.3 \%$ to $6.3 \%$, then the stability decreases to $10.41 \mathrm{kN}$ with the increase of the asphalt-aggregate ratio from $6.3 \%$ to $7.3 \%$. Similarly, the maximum values of stability for SMA-II-2 and SMA-II-3 are $10.35 \mathrm{kN}$ when the asphalt-aggregate ratio is $8.1 \%$ and $10.67 \mathrm{kN}$ when the asphalt-aggregate ratio is $7.1 \%$. Thus, the optimal asphalt contents of SMA-II-1, SMA-II-2 and SMA-II-3 are 6.3\%, 7.8\% and 6.9\%. Then, fiber was added to all SMA-II mixtures in different proportions; meanwhile, asphalt content should increase. The Marshall test results of SMA-II-1 are shown in Table 9. 
Table 9. Basic parameters and Marshall volumetric indicators of the mixture.

\begin{tabular}{|c|c|c|c|c|c|c|c|c|}
\hline Mixture & $\begin{array}{c}\text { Fiber } \\
\text { Content } / \%\end{array}$ & $\begin{array}{l}\text { Asphalt- } \\
\text { Aggregate } \\
\text { Ratio/\% }\end{array}$ & $\begin{array}{c}\text { Bulk } \\
\text { Density } \\
\mathrm{g} / \mathrm{cm}^{3}\end{array}$ & VV/\% & VWA/\% & VFA/\% & Stability/kN & $\mathrm{FL} / \mathrm{mm}$ \\
\hline \multirow{15}{*}{ SMA-II-1 } & \multirow{3}{*}{0.1} & 6.2 & 2.441 & 3.62 & 17.6 & 79.4 & 10.52 & 3.52 \\
\hline & & 6.5 & 2.437 & 3.23 & 18.3 & 82.4 & 10.73 & 3.76 \\
\hline & & 6.8 & 2.416 & 2.64 & 18.8 & 86.0 & 10.15 & 4.21 \\
\hline & \multirow{3}{*}{0.15} & 6.3 & 2.438 & 3.42 & 17.7 & 80.7 & 10.47 & 3.35 \\
\hline & & 6.6 & 2.431 & 2.71 & 17.9 & 84.9 & 10.98 & 3.57 \\
\hline & & 6.9 & 2.409 & 2.43 & 18.6 & 87.0 & 10.15 & 4.12 \\
\hline & \multirow{3}{*}{0.2} & 6.4 & 2.436 & 3.31 & 17.4 & 81.0 & 10.59 & 3.54 \\
\hline & & 6.7 & 2.433 & 3.03 & 17.5 & 82.7 & 11.06 & 3.88 \\
\hline & & 7.0 & 2.420 & 2.33 & 18.1 & 87.1 & 10.71 & 4.36 \\
\hline & \multirow{3}{*}{0.25} & 6.4 & 2.435 & 3.52 & 17.4 & 79.8 & 10.84 & 3.67 \\
\hline & & 6.7 & 2.421 & 3.11 & 17.2 & 81.9 & 10.75 & 4.06 \\
\hline & & 7.0 & 2.402 & 2.73 & 18.2 & 85.0 & 10.23 & 4.63 \\
\hline & \multirow{3}{*}{0.3} & 6.4 & 2.425 & 3.23 & 17.7 & 81.8 & 10.63 & 3.73 \\
\hline & & 6.8 & 2.406 & 2.61 & 17.2 & 84.8 & 10.41 & 4.39 \\
\hline & & 7.0 & 2.398 & 2.23 & 17.9 & 87.5 & 9.97 & 4.75 \\
\hline
\end{tabular}

According to Marshall test results in Table 9 and calculation methods in the Chinese specification JTG40-2004 [39], OAC (the optimal asphalt content), $\mathrm{OAC}_{\min }$ and $\mathrm{OAC}_{\max }$ of SMA-II-1 with different fiber contents are shown in Figure 4:

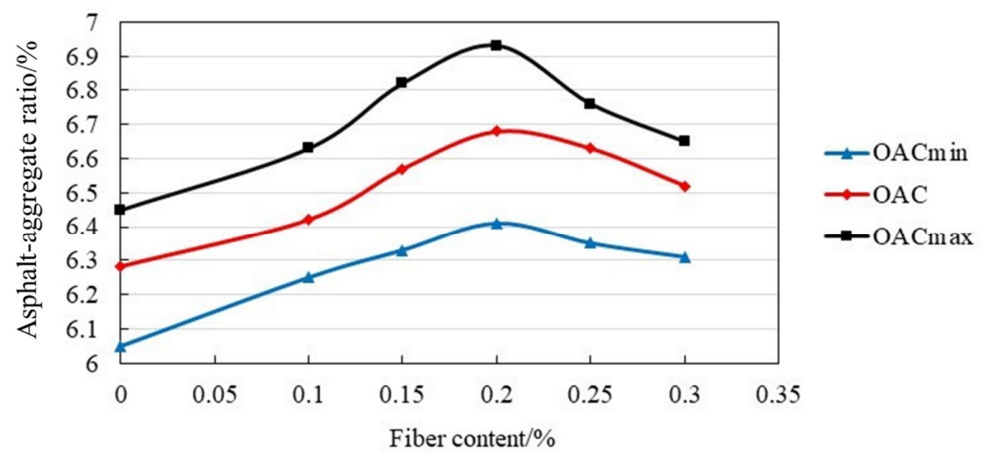

Figure 4. Relationship between fiber content and asphalt-aggregate ratio of SMA-II-1.

In Figure 4, before the peak of the curve, the optimal asphalt content (OAC) increases with increasing fiber content. At the peak, OAC increases by about $0.4 \%$ because of the presence of the fiber. After the peak, OAC reduces gradually with increasing fiber content. Figure 5 shows that there is an extremum for the Marshall stability of the asphalt mixture with different fiber contents and asphalt-aggregate ratios. The reason is that the specific surface area of the fiber will increase with the addition of fiber that will adsorb a certain amount of asphalt, then the OAC will increase. But with a further increase of fiber content, the specific surface area of the fiber will decrease because excess fiber can reduce the dispersity so OAC will decrease accordingly. Therefore, in this test, the optimal amount of polyester fiber is $0.18 \%$ while the optimal asphalt-aggregate ratio is $6.6 \%$. 


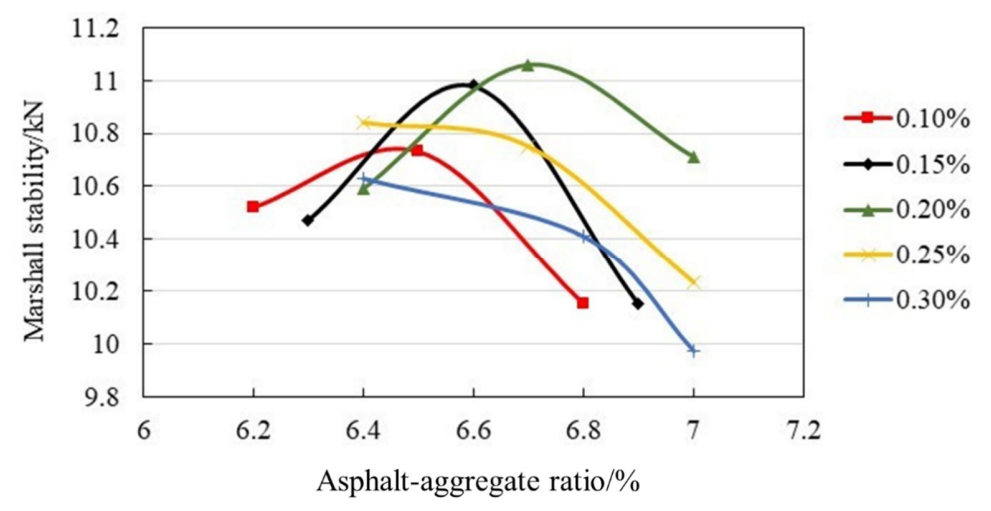

Figure 5. Stability under different fiber content and asphalt-aggregate ratio.

Similarly, the test results of SMA-II-2 and SMA-II-3 are shown in Figures 6 and 7, respectively. The optimal fiber content and optimal asphalt-aggregate ratio of SMA-II-2 are $0.27 \%$ and $8.1 \%$. The optimal fiber content and optimal oil stone ratio of SMA-II-3 are $0.21 \%$ and $7.1 \%$.

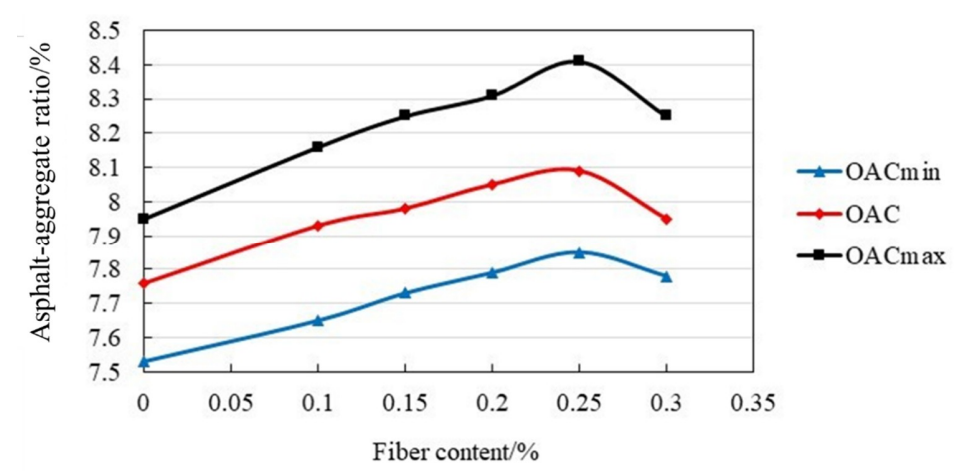

Figure 6. Relationship between fiber content and asphalt-aggregate ratio of SMA-II-2.

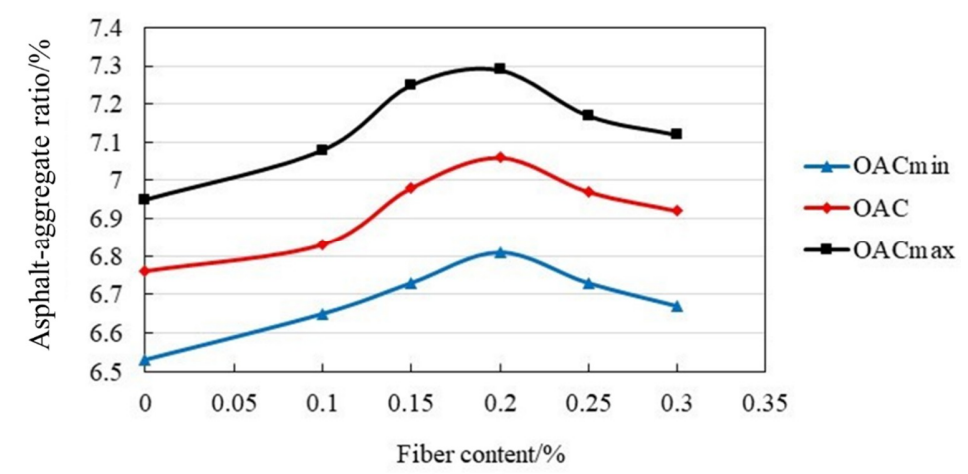

Figure 7. Relationship between fiber content and asphalt-aggregate ratio of SMA-II-3.

\subsection{Study on Key Controlling Indices of Mix Proportion}

To guide the mix proportion design of the mixture, the influence of the passing rate on the air voids of the mixture and the influence of the filler-asphalt ratio on the performance of SMA-II were studied.

\subsubsection{The Influence of 1.18-mm and 0.075-mm Sieve Passing Rate on Air Voids of the Mixture}

The key control sieves are usually $1.18-\mathrm{mm}$ and $0.075-\mathrm{mm}$ sieves for a mixture with a $4.75-\mathrm{mm}$ nominal maximum particle size. A 1.18-mm sieve can control the ratio of coarse and fine aggregates to form a coarse aggregate skeleton structure, a $0.075-\mathrm{mm}$ sieve can influence the air voids of a mixture, which, as a result, can further influence the road performance of the mixture. 
In Table 10, the asphalt content for three gradations (without fiber) are still $6.5 \%$. As a control variable for each gradation, the passing rates of the $1.18-\mathrm{mm}$ sieve are $36.3 \%, 55.3 \%$ and $47.1 \%$ in SMA-II-1, SMA-II-2 and SMA-II-3, respectively. The mineral filler content of each gradation is $8.5 \%, 9.5 \%, 10.5 \%$, respectively. Specimens of all gradations are made by way of the gyratory compaction method (125 times compaction). Table 11 presents the test results of the air voids of gyratory compaction specimens.

Table 10. Gradation with different passing rate of $1.18-\mathrm{mm}$ and $0.075-\mathrm{mm}$ sieves.

\begin{tabular}{ccccccccc}
\hline Gradations & $\mathbf{9 . 5}$ & $\mathbf{4 . 7 5}$ & $\mathbf{2 . 3 6}$ & $\mathbf{1 . 1 8}$ & $\mathbf{0 . 6}$ & $\mathbf{0 . 3}$ & $\mathbf{0 . 1 5}$ & $\mathbf{0 . 0 7 5}$ \\
\hline SMA-II-1-1 & 100 & 76.7 & 55.6 & 36.3 & 23.3 & 18.3 & 13.5 & 8.5 \\
SMA-II-1-2 & 100 & 76.7 & 55.6 & 36.3 & 23.3 & 18.3 & 13.5 & 9.5 \\
SMA-II-1-3 & 100 & 76.7 & 55.6 & 36.3 & 23.3 & 18.3 & 13.5 & 10.5 \\
SMA-II-2-1 & 100 & 92 & 72.3 & 55.3 & 37.7 & 19.4 & 12.9 & 8.5 \\
SMA-II-2-2 & 100 & 92 & 72.3 & 55.3 & 37.7 & 19.4 & 12.9 & 9.5 \\
SMA-II-2-3 & 100 & 92 & 72.3 & 55.3 & 37.7 & 19.4 & 12.9 & 10.5 \\
SMA-II-3-1 & 100 & 88.2 & 67.6 & 47.1 & 47.1 & 29.4 & 16.5 & 8.5 \\
SMA-II-3-2 & 100 & 88.2 & 67.6 & 47.1 & 47.1 & 29.4 & 16.5 & 9.5 \\
SMA-II-3-3 & 100 & 88.2 & 67.6 & 47.1 & 47.1 & 29.4 & 16.5 & 10.5 \\
\hline
\end{tabular}

Table 11. Air voids of gyratory compaction specimens.

\begin{tabular}{cccccccccc}
\hline Test Items & $\mathbf{1 - 1}$ & $\mathbf{1 - 2}$ & $\mathbf{1 - 3}$ & $\mathbf{2 - 1}$ & $\mathbf{2 - 2}$ & $\mathbf{2 - 3}$ & $\mathbf{3 - 1}$ & $\mathbf{3 - 2}$ & $\mathbf{3 - 3}$ \\
\hline Bulk density $/\left(\mathrm{g} \cdot \mathrm{m}^{-3}\right)\left(\mathrm{cm}^{-3}\right)$ & 2.318 & 2.406 & 2.422 & 2.396 & 2.36 & 2.328 & 2.374 & 2.396 & 2.457 \\
Air voids/\% & 6.31 & 4.06 & 3.24 & 3.72 & 4.32 & 5.18 & 4.56 & 3.82 & 2.75 \\
\hline
\end{tabular}

Figures 8 and 9 show that, with the increase of mineral filler content, the air voids of both SMA-II-1 and SMA-II-3 decrease gradually but at different rates, that is, the variation of mineral filler content has a deeper influence on the air voids of SMA-II-1 than that of SMA-II-3. In contrast, the air voids of SMA-II-2 increase with the increase of the mineral filler content. According to the test results in Table 10, the mineral filler content changes from $8.5 \%$ to $9.5 \%$ and then to $10.5 \%$, while the air voids of SMA-II-1 decrease by $33.6 \%$ and $29.3 \%$, respectively, the air voids of SMA-II-3 decrease by $16.2 \%$ and $17.5 \%$, respectively and the air voids of SMA-II-2 increase by $13.9 \%$ and $16.6 \%$, respectively. The average slopes of the air voids curves of SMA-II-1, SMA-II-2 and SMA-II-3 shown in Figure 8 are $-1.535,0.73$ and -0.905 , respectively.

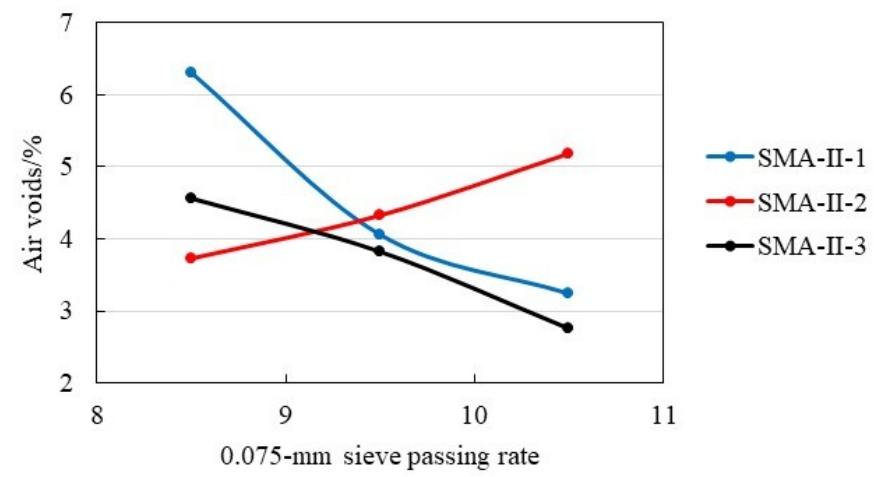

Figure 8. Change curves of the air voids of SMA-II-1, SMA-II-2 and SMA-II-3.

The changing trends of the air voids of II-1 resemble those of II-3, which is because the amount of coarse aggregate in these two gradations are in the majority, and fine aggregate, especially mineral filler content, plays a significant role in the change of air voids. However, the air voids of the gap-graded are less sensitive to changes in the mineral filler content; hence, a qualified gradation is easier to design. 
For SMA-II-2 with a large amount of fine aggregate, a slight change of the mineral powder content has little effect on the air voids of the mixture; meanwhile, the oil-stone ratio $6.5 \%$ is low, which will make the air voids increase with the increase of the mineral filler content. In this case, the average slopes of the air voids curves show that the change in the air voids with mineral filler content is relatively stable; however, the change range of the fine aggregate content (the interval is $8.2 \%$ and $10.8 \%$ ) is much larger than that of the mineral filler content (the interval is $1 \%$ ). Therefore, the passing rate of the $1.18-\mathrm{mm}$ sieve has a more remarkable influence on the air voids of the mixture.

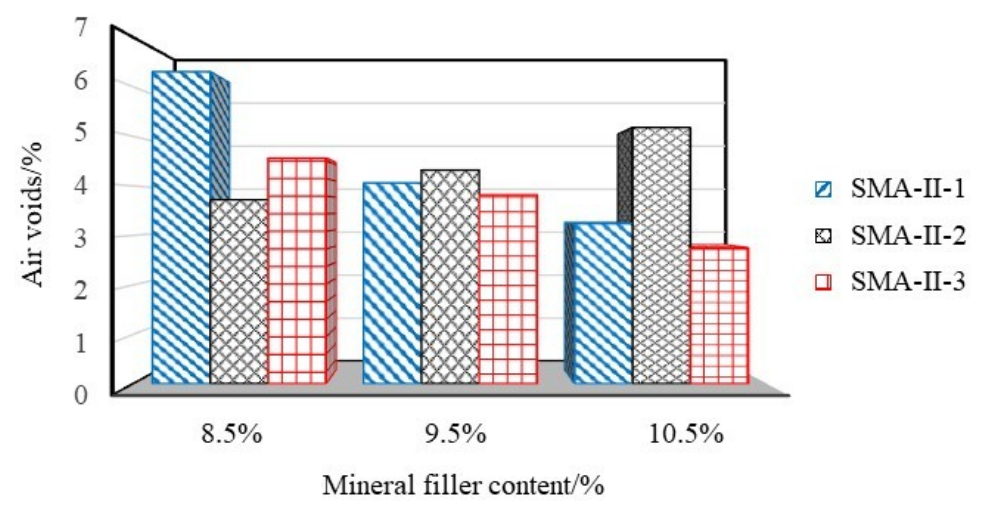

Figure 9. The influence of mineral filler content on air voids.

\subsubsection{The Influence of Filler-Asphalt Ratio on the Performance of SMA-II}

Mineral filler is of vital importance to asphalt mixture. The cohesion between asphalt and aggregate is generated by an asphalt absorbing mineral filler based on a thin asphalt film, that is, the combination of asphalt and mineral filler is the real binder. The interaction between the asphalt and mineral filler was the determining factor of the formation of the asphalt mixture structure, which is directly related to the strength, temperature stability and aging rate of the asphalt mixture [40]. Therefore, it is necessary to study asphalt and mineral filler as a group. In this section, the freeze-thaw splitting test and the low-temperature bend test of SMA-II with a different filler-asphalt ratio were conducted to compare the influence of different filler-asphalt ratios on the water stability and low temperature properties of the mixture. SMA-II-3 without fiber was adopted in this test. Gradations are shown in Table 12:

Table 12. Gradations with different mineral filler contents.

\begin{tabular}{ccccc}
\hline Gradations & $\begin{array}{c}\text { Passing Rate of } \\
\text { 1.18-mm Sieve }\end{array}$ & $\begin{array}{c}\text { Passing Rate of } \\
\text { 0.075-mm Sieve }\end{array}$ & $\begin{array}{c}\text { Effective } \\
\text { Asphalt Content }\end{array}$ & $\begin{array}{c}\text { Filler-Asphalt } \\
\text { Ratio }\end{array}$ \\
\hline $3-1$ & 47.1 & 10.5 & 6.5 & 1.62 \\
$3-2$ & 47.1 & 10.5 & 7.5 & 1.40 \\
$3-3$ & 47.1 & 10.5 & 8.5 & 1.24 \\
$3-4$ & 47.1 & 10.5 & 9.5 & 1.11 \\
$3-5$ & 47.1 & 10.5 & 10.5 & 1.00 \\
\hline
\end{tabular}

Specimens of five gradations in Table 12 were made with the optimal asphalt content, the rest of the results of the freeze-thaw splitting test and the low temperature bend test are shown in Tables 13 and 14. Original splitting strength $\left(R_{\mathrm{T} 1}\right)$, freeze-thaw splitting strength $\left(R_{\mathrm{T} 2}\right)$ and Tensile strength ratio (TSR) were calculated based on Equations (A2)-(A4) shown in Appendix B. Flexural tensile strength $R_{\mathrm{B}}$, ultimate tensile strain $\varepsilon_{\mathrm{B}}$ and flexural stiffness modulus $S_{\mathrm{B}}$ were calculated based on Equations (A6)-(A8) shown in Appendix B. 
Table 13. Results of the freeze-thaw splitting test.

\begin{tabular}{ccccc}
\hline Gradations & $\begin{array}{c}\text { Original Splitting } \\
\text { Strength } \\
\left(\boldsymbol{R}_{\mathbf{T} 1) / \mathbf{M P a}}\right.\end{array}$ & $\begin{array}{c}\text { Freeze-Thaw } \\
\text { Splitting Strength } \\
\left(\boldsymbol{R}_{\mathbf{T} 2}\right) / \mathbf{M P a}\end{array}$ & $\begin{array}{c}\text { Tensile Strength } \\
\text { Ratio (TSR)/\% }\end{array}$ & Requirement/\% \\
\hline $3-1$ & 0.8465 & 0.7085 & 83.70 & \\
$3-2$ & 0.8916 & 0.7737 & 86.78 & $\geq 80$ \\
$3-3$ & 0.9049 & 0.8058 & 89.05 & \\
$3-4$ & 0.9143 & 0.8386 & 91.72 & \\
$3-5$ & 0.9485 & 0.9021 & 95.11 & \\
\hline
\end{tabular}

Table 14. Results of the low-temperature bend test.

\begin{tabular}{cccccc}
\hline Test Items & \multicolumn{5}{c}{ Test Values } \\
\hline Filler-asphalt ratio & 1.62 & 1.40 & 1.24 & 1.11 & 1.00 \\
Maximum failure load/N & 1315.5 & 1272.1 & 1248.7 & 1205.8 & 1126.3 \\
Flexural strength $\left(R_{\mathrm{B}}\right) / \mathrm{MPa}$ & 10.739 & 10.385 & 10.193 & 9.844 & 9.194 \\
Ultimate tensile strain $\left(\varepsilon_{\mathrm{B}}\right) / \mu \varepsilon$ & 11,445 & 12,128 & 12,758 & 13,388 & 14,490 \\
Flexural stiffness modulus $\left(S_{\mathrm{B}}\right) / \mathrm{MPa}$ & 938.32 & 856.31 & 798.99 & 735.29 & 634.54 \\
\hline
\end{tabular}

In Table 13, all TSRs of SMA-II-3 with different filler-asphalt ratios can meet the requirements of Chinese specification JTG F40-2004 [39]. The splitting strength and TSR of all mixtures increased gradually with the decrease of the filler-asphalt ratio. The splitting strength decreases rapidly when the filler-asphalt ratio is 1.6, which indicates a rapid increase of air voids. TSR increases rapidly when the filler-asphalt ratio is 1.0 and all values of TSR are more than $95 \%$, which indicates that the air voids are very small. Hence, the recommended range of filler-asphalt ratio should be from $1.1 \%$ to $1.4 \%$.

In Figures 10 and 11, with the increase of the filler-asphalt ratio, the maximum flexural strain curve of the mixture is a concave decreasing curve, while the flexural stiffness modulus curve is a convex increasing curve. All maximum tensile strains in this test are more than 10,000, which is much larger than the 2800 that is required by Chinese specification JTG F40-2004 [39]. As a matter of fact, when the filler-asphalt ratio is small, because of the existence of too much free asphalt, the flexibility of the mixture enhances, then the bending tensile strain becomes smaller. The increase in the filler-asphalt ratio will result in the decrease of free asphalt, combined with the absorption and reinforcement of fiber, the flexural stiffness modulus increases while the bending tensile strain decreases. To sum up, the recommended filler-asphalt ratio should be from $1.0 \%$ to $1.6 \%$ from the perspective of low-temperature performance.

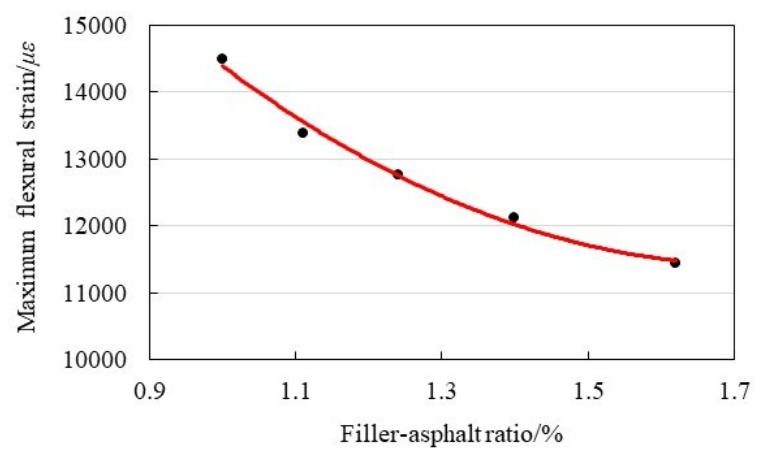

Figure 10. Relationship between maximum flexural strain and filler-asphalt ratio of SMA-II-3 mixture beam at $-10^{\circ} \mathrm{C}$, loading rate of $50 \mathrm{~mm} / \mathrm{min}$. 


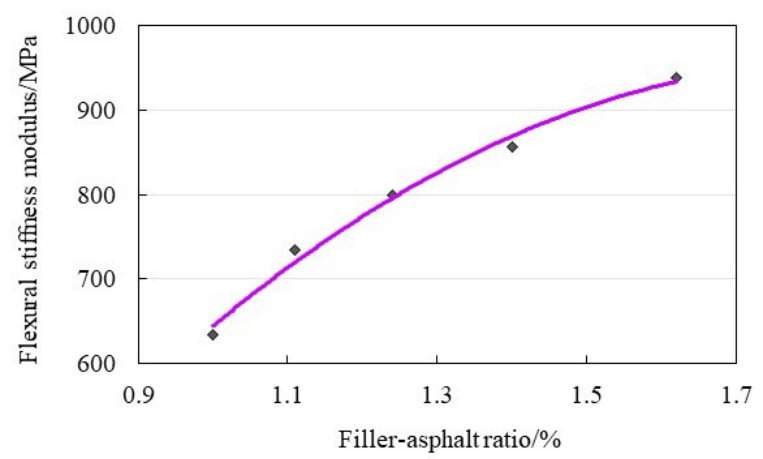

Figure 11. Relationship between flexural stiffness modulus and filler-asphalt ratio of SMA-II-3 mixture at $-10{ }^{\circ} \mathrm{C}$, loading rate of $50 \mathrm{~mm} / \mathrm{min}$.

\section{Results and Discussion}

\subsection{High-Temperature Performance}

The Rutting Test shall be executed by reference to the test method of T 0719-2011 in Chinese specification JTG E20-2011 [32]. The material composition of specimens used in this test are based on the results of Figures 4,6 and 7. Dynamic stability (DS) was calculated based on Equation (A1), shown in Appendix B. Test results are in Table 15:

Table 15. Test results of dynamic stability of SMA-II.

\begin{tabular}{ccccc}
\hline Mixture & Specimen 1 & Specimen 2 & Specimen 3 & $\begin{array}{c}\text { Mean Value of Dynamic } \\
\text { Stability/(Times/mm) }\end{array}$ \\
\hline SMA-II-1 & 3182 & 2930 & 3029 & 3047 \\
SMA-II-2 & 2540 & 2461 & 2944 & 2648 \\
SMA-II-3 & 2930 & 3316 & 3264 & 3170 \\
\hline
\end{tabular}

As shown in Table 15, Both mean values of dynamic stability of SMA-II-1 and SMA-II-3 are over 3000, which are greater than 2800 that is required in hot summer heavy traffic area in the Chinese specification JTG F40-2004 [39]. Dynamic stability of SMA-II-2 was slightly less than the highest value 3000 in the Chinese specification JTG F40-2004 [39], which indicates the relatively poor high-temperature performance of SMA-II-2.

\subsection{Water Stability}

In this section, Vacuum Saturated Marshall Stability and Freeze-thaw Splitting tests shall be respectively executed by reference to the test method of T 0709-2011 and T 0729-2000 in Chinese specification JTG E20-2011 [32]. The material composition of specimens used in this test are based on the results of Figures 4,6 and 7. In the vacuum saturated Marshall stability test, specimens were cylinders ( $\varphi 101.6 \mathrm{~mm} \times 63.5 \mathrm{~mm}$ ), which were made according to $\mathrm{T} 0702-2011$ [32]. Specimens were first placed in a vacuum dryer with the water inlet hose closed, then the vacuum pump was turned on to make the vacuum degree $97.3 \mathrm{kPa}$ or above for $15 \mathrm{~min}$. Thirdly, the water inlet hose was opened to let the cold-water flow enter to completely immerse the specimen in water for $15 \mathrm{~min}$. At last, after normal pressure was restored, specimens were taken out from the vacuum dryer and put in a water bath with a constant temperature for $48 \mathrm{~h}$. Test results are shown in Table 16. Residual stability $\mathrm{MS}_{0}^{\prime}$ was calculated based on Equation (A5) in Appendix B. Original splitting strength $\left(R_{\mathrm{T} 1}\right)$, freeze-thaw splitting strength $\left(R_{\mathrm{T} 2}\right)$ and Tensile strength ratio (TSR) were calculated based on Equations (A2)-(A4) in Appendix B. 
Table 16. Results of vacuum saturated Marshall stability test.

\begin{tabular}{ccccc}
\hline Mixture & $\begin{array}{c}\text { Marshall Stability } \\
(\mathbf{M S}) / \mathbf{k N}\end{array}$ & $\begin{array}{c}\text { Vacuum Saturated Marshall } \\
\text { Stability }\left(\mathbf{M S}_{\mathbf{2}}\right) \mathbf{k N}\end{array}$ & $\begin{array}{c}\text { Residual Marshall } \\
\text { Stability }\left(\mathbf{M S}_{0}^{\prime}\right) / \%\end{array}$ & Requirement/\% \\
\hline SMA-II-1 & 10.93 & 10.03 & 91.8 & $\geq 85$ \\
SMA-II-2 & 10.21 & 9.52 & 93.2 & \\
SMA-II-3 & 11.02 & 9.96 & 90.4 & \\
\hline
\end{tabular}

The results in Tables 16 and 17 show that all the performance indicators of the water stability of SMA-II-1, SMA-II-2 and SMA-II-3 can meet Chinese specification JTG F40-2004 [39]. Among the test values, the test value of the water stability of SMA-II-2 is the highest.

Table 17. Results of Freeze-thaw splitting test.

\begin{tabular}{ccccc}
\hline Mixture & $\begin{array}{c}\text { Original Splitting } \\
\text { Strength }\left(\boldsymbol{R}_{\mathbf{T} 1}\right) / \mathbf{M P a}\end{array}$ & $\begin{array}{c}\text { Freeze-Thaw } \\
\text { Splitting Strength } \\
\left(\boldsymbol{R}_{\mathrm{T} 2}\right) / \mathbf{M P a}\end{array}$ & $\begin{array}{c}\text { Tensile Strength } \\
\text { Ratio (TSR)/\% }\end{array}$ & Requirement/\% \\
\hline SMA-II-1 & 1.13 & 1.01 & 89.4 & $\geq 80$ \\
SMA-II-2 & 1.07 & 0.97 & 90.7 & 88.9 \\
SMA-II-3 & 1.17 & 1.04 & 8 & \\
\hline
\end{tabular}

\subsection{Skid Resistance}

The sand patch method and portable pendulum tester method were adopted to measure texture depth and the friction coefficient of mixture surface, respectively. The sand patch method and the portable pendulum tester method were executed by reference to the test method of $\mathrm{T}$ 0731-2000 in specification JTG E20-2011 [32] and T 0964-2008 in Chinese specification JTG E60-2008, respectively [41]. The material composition of specimens used in this test are based on the results of Figures 4, 6 and 7 . The texture depth of asphalt mixture was calculated based on the Equation (A9) in Appendix B. Test results are shown in Table 18:

Table 18. Test results of skid resistance performance.

\begin{tabular}{ccc}
\hline Mixture & Texture Depth (TD)/mm & BPN \\
\hline SMA-II-1 & 1.02 & 76 \\
SMA-II-2 & 0.87 & 66 \\
SMA-II-3 & 0.96 & 73 \\
\hline
\end{tabular}

The test results in Table 18 indicate that the Texture Depth of SMA-II-1 and SMA-II-2 are better because of the high content of coarse aggregate.

\subsection{Low-Temperature Bend Test}

The beam bend test evaluates crack resistance at a low temperature based on flexural tensile strength, flexural tensile strain and bending stiffness modulus when the mixture is damaged. The material composition of the specimens used in this test are based on the results of Figures 4, 6 and 7. A low temperature bend test, as shown in Figure 11, was executed with reference to the test method of T 0715-2011 in Chinese specification JTG E20-2011 [32]. Table 19 and Figure 12 are the results of the low temperature bend test. 


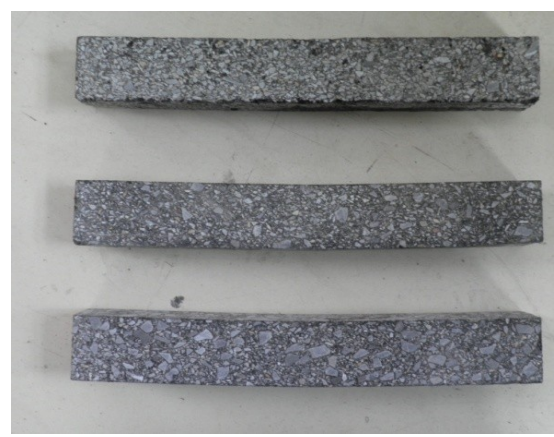

(a)

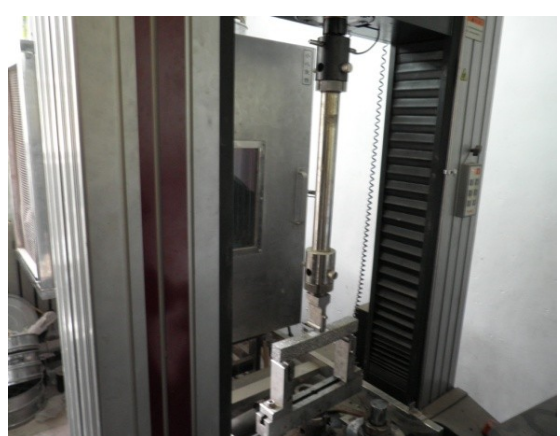

(b)

Figure 12. Three specimens (a) and Materials Testing System (MTS) (b) for low temperature bend test at $-10{ }^{\circ} \mathrm{C}$, at loading rate of, $50 \mathrm{~mm} / \mathrm{min}$.

Table 19. Results of low temperature bend test.

\begin{tabular}{cccccc}
\hline Mixture & Asphalt & $\begin{array}{c}\text { Fiber } \\
\text { Content/\% }\end{array}$ & $\begin{array}{c}\text { Flexural } \\
\text { Strength } \\
\mathbf{R}_{\mathbf{B}} / \mathbf{M P a}\end{array}$ & $\begin{array}{c}\text { Ultimate } \\
\text { Tensile } \\
\text { Strain } \mathbf{E}_{\mathbf{B}} / \boldsymbol{\mu \varepsilon}\end{array}$ & $\begin{array}{c}\text { Flexural Stiffness } \\
\text { Modulus S }\end{array}$ \\
\hline SMA-I & SBS-modified & 0 & 12.91 & 7438.7 & 1735.74 \\
SMA-II-1 & Rubberized & 0.18 & 10.12 & $10,072.1$ & 1005.02 \\
SMA-II-3 & Rubberized & 0.21 & 9.75 & $12,386.3$ & 787.06 \\
SMA-II-2 & Rubberized & 0.27 & 9.36 & $15,451.3$ & 605.54 \\
\hline
\end{tabular}

According to the results shown in Table 19, the flexural strength of the SBS-modified SMA-I mixture is the largest, while the maximum flexural strain is the smallest. The flexural strengths of all SMA-II mixtures are lower than those of SMA-I mixture, while, in contrast, the maximum flexural strains are much larger than those of SMA-I. The flexural strength of SMA-II-1, II-3 and II-2 respectively are $78.4 \%, 75.5 \%$ and $72.5 \%$ of that of SMA-I, the maximum flexural strains respectively are higher than that of SMA-I by $26.1 \%, 39.9 \%$ and $51.9 \%$. The maximum flexural strain of SMA-I is 7438.7 , while for all SMA-II mixtures, the test values are greater than 10,000-the flexural strain of SMA-II-2 is more than 15,000, which is far greater than the 3000 that is required by Chinese specification JTG F40-2004 [39]. The flexural stiffness modulus of all SMA-II mixtures is lower than that of the SMA-I mixture-the flexural stiffness modulus of II-2 is only 35\% of that of SMA-I. All of these demonstrate the good low-temperature flexibility, deformation and crack resistance of SMA-II.

Figure 13 shows that the failure load of the SMA-I mixture decreases rapidly after reaching the maximum, which indicates there is obvious brittle fracture. The load-strain curve of SMA-II is a flat parabolic curve without a brittle fracture point. Among the three load-strain curves, SMA-II-1 has the maximum failure load but the minimum strain interval. SMA-II-2 has the minimum failure load but the maximum strain interval, as well as the flattest load-strain curve, which is related to the high asphalt content $8.1 \%$ of SMA-II-2. The load-strain curve of SMA-II-3 is in between the load-strain curves of SMA-II-1 and SMA-II-2.

To sum up, the low-temperature performance of the SMA-I (SBS-modified) mixture is much worse than that of the rubberized SMA-II mixtures, which indicates that the asphalt-rubber binder is the major factor that affects the low-temperature performance of the mixture. The reason is due to the swelling reaction between the crumb rubber and the asphalt-the rubber swollen particles can uniformly suspend and disperse in asphalt, which will result in the change of the asphalt's interfacial property; hence, the viscosity of the asphalt-rubber binder increases and the temperature sensitivity lowers, which will improve the low temperature performance of the asphalt mixture. 


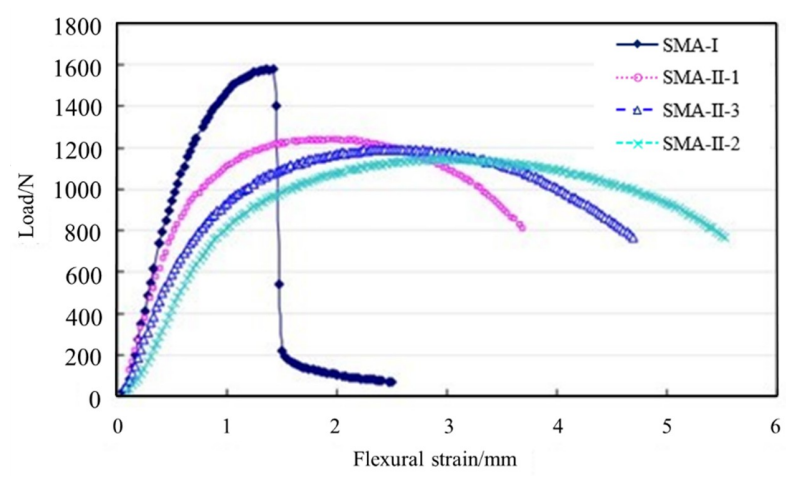

Figure 13. Relationship between load and flexural strain of low temperature bend test at $-10{ }^{\circ} \mathrm{C}$, at loading rate of $50 \mathrm{~mm} / \mathrm{min}$.

\subsection{Analysis of the Bending Strain Energy Density}

Asphalt mixture can be regarded as an elastic material at low temperatures, for which the destructive process is the process of energy dissipation. Specifically, first, the work of external force on the material will be converted into elastic strain energy, then, elastic strain energy turns into surface energy when a new surface appears with the occurrence and development of cracks. Normally, the more elastic strain energy that is stored in the asphalt mixture, the better the low temperature crack resistance. Hence, to some extent, the bending strain energy density function is a preferable method for evaluating the low temperature performance of asphalt mixture [42]; the function is shown as (5):

$$
W=\int_{0}^{\varepsilon_{0}} \sigma_{i j} d \varepsilon_{i j}
$$

where $W$ is the strain energy density function. $\sigma_{i j}$ is the stress value. $\varepsilon_{i j}$ is the strain value. $\varepsilon_{0}$ is the strain value corresponding to the maximum stress.

According to the test results shown in Figure 13, the stress-strain curve was plotted. In order to achieve a good correlation between the fitted curve and the test data, the fourth power parabolic equation was adopted. Then, the critical strain energy density could be obtained by integral calculation according to the regression equation. The calculation results are shown in Table 20:

Table 20. Bending strain energy density of asphalt mixtures.

\begin{tabular}{cc}
\hline Mixture & Bending Strain Energy Density $/\left(\mathbf{k J} / \mathbf{m}^{3}\right)$ \\
\hline SMA-I & 14.75 \\
SMA-II-1 & 17.72 \\
SMA-II-3 & 20.38 \\
SMA-II-2 & 24.28 \\
\hline
\end{tabular}

Table 20 indicates that the bending strain energy density of rubberized SMA-II mixtures is significantly greater than that of SBS-modified SMA-I mixture. The strain energy density of SMA-II-1, SMA-II-3 and SMA-II-2 increases by $20.1 \%, 38.2 \%$ and $64.6 \%$ more than that of the SMA-I mixture. The SMA-II-2 mixture, with high asphalt content and polyester fiber, has the highest bending strain energy density. Therefore, from the perspective of crack resistance, SMA-II mixtures are better than SMA-I mixtures.

\subsection{Life-Cycle Cost Analysis of Small Particle-Size Asphalt Pavement}

In this section, life-cycle cost analysis (LCCA) was used to assess the economic effectiveness of small particle-size thin overlay on an SMA asphalt pavement and a typical Hot Mixed Asphalt (HMA) 
pavement. LCCA is a method based on the principles of economic analysis, which has been widely applied in pavement design and management [43].

Among the economic indices of the economic evaluation of projects, the internal rate of return (IRR), equivalent uniform annual cost (EUAC), benefit/cost ratio $(\mathrm{B} / \mathrm{C})$ and Net Present Value $(N P V)$ are the most commonly used. In this case study, Net Present Value (NPV) was selected as the economic indicator. Equation (6) can be applied for an asphalt pavement case [43].

$$
N P V=\text { Initial } \quad \text { Cons.Cost }+\sum_{K=1}^{N} \text { Future } \operatorname{Cos} t_{K}\left[\frac{1}{(1+i)^{n_{k}}}\right]-\text { Salvage Value }\left[\frac{1}{(1+i)^{n_{e}}}\right]
$$

where:

$N=$ number of future costs incurred over the analysis period,

$i=$ discount rate in percent,

$n_{K}=$ number of years from the initial construction to the Kth expenditure,

$n_{e}=$ analysis period in years.

In this case study, it is assumed that the AC-13 thin overlay was applied to the ordinary HMA pavement every five years. The SPS thin overlay was applied to an SMA pavement every seven years because of the good crack resistance, there will therefore be one less thin overlay treatment than an ordinary HMA pavement in a 20-year service life.

For initial construction cost, according to average market price, the price of ordinary HMA was set to $\$ 70 /$ ton, the price of small particle-size asphalt mixture was set to $\$ 100 /$ ton. The analysis results can be seen in Table 21. The design life was 20 years, the discount rate in percent (i) was 3\%, the annual maintenance cost of a new HMA pavement was $11 \%$ of the initial construction cost and the annual maintenance cost of a new SMA pavement was $9 \%$ of the initial construction cost. The total cost was calculated based on one $3.5 \mathrm{~m}$-wide lane $/ \mathrm{km}$.

Table 21. Life-cycle cost analysis of HMA and SMA pavements with SPS asphalt overlay.

\begin{tabular}{|c|c|c|c|c|c|c|}
\hline $\begin{array}{c}\text { Mixture } \\
\text { Type }\end{array}$ & Age & Project & $\operatorname{Cost} / \$$ & \multicolumn{2}{|c|}{$\mathrm{NPV} / \$$} & $\begin{array}{l}\text { Total of } \\
\text { NPV/\$ }\end{array}$ \\
\hline \multirow{5}{*}{ HMA } & 0 & $\begin{array}{l}\text { New pavement (thickness of top, middle, } \\
\text { and bottom layer is } 4,6 \text {, and } 8 \mathrm{~cm} \text { ) }\end{array}$ & 107,939 & & 939 & \multirow{5}{*}{336,904} \\
\hline & 5 & $3 \mathrm{~cm} \mathrm{AC}-13$ thin overlay & 17,990 & 15,518 & \multirow{4}{*}{228,965} & \\
\hline & 10 & $3 \mathrm{~cm} \mathrm{AC}-13$ thin overlay & 17,990 & 13,386 & & \\
\hline & 15 & $3 \mathrm{~cm} \mathrm{AC}-13$ thin overlay & 17,990 & 11,547 & & \\
\hline & Other & $\begin{array}{l}\text { Total of other maintenance costs } \\
\text { (Annual cost } \$ 11,873 \text { ) }\end{array}$ & 189,968 & 188,514 & & \\
\hline \multirow{4}{*}{ SMA } & 0 & $\begin{array}{l}\text { New pavement (thickness of top, middle, } \\
\text { and bottom layer is } 3,6 \text {, and } 8 \mathrm{~cm} \text { ) }\end{array}$ & 109,652 & \multicolumn{2}{|c|}{109,652} & \multirow{4}{*}{291,604} \\
\hline & 7 & $2 \mathrm{~cm}$ SPS asphalt overlay & 17,133 & 13,930 & \multirow{3}{*}{181,952} & \\
\hline & 14 & $2 \mathrm{~cm}$ SPS asphalt overlay & 17,133 & 11,327 & & \\
\hline & Other & $\begin{array}{l}\text { Total of other maintenance costs } \\
\text { (Annual cost \$9869) }\end{array}$ & 167,773 & 156,695 & & \\
\hline
\end{tabular}

Table 21 shows that, compared with a traditional HMA pavement, the initial cost of an SMA asphalt pavement with an SPS asphalt mixture top layer increases from $\$ 107,939 / \mathrm{km}$ to $\$ 109,652 / \mathrm{km}$. But the maintenance cost decreases by $20.5 \%$ (from $\$ 228,965$ to $\$ 181,952$ ) because of the reduction of maintenance times. Across the whole service life, the total NPV decreases by $13.4 \%$ (from $\$ 336,904$ to $\$ 291,604)$. Considering the increase of user delay costs during the maintenance period and the high 
service level of an SPS asphalt mixture pavement, the total NPV of an SPS asphalt mixture pavement would be lower, which demonstrates the better life-cycle economic benefit of SPS asphalt mixture thin overlay over traditional AC-13 thin overlay.

\section{Conclusions}

A mix design of small particle-size (SPS) asphalt mixture for controlling cracks in pavement surfaces was studied. The gradation was improved SMA-II dense gradation, and the binder was asphalt-rubber binder with polyester fiber used to enhance crack resistance. The asphalt mixture presented in this paper can be used as a hot mix asphalt thin overlay, which is an effective preventive maintenance method or pavement surface layer to improve the crack resistance performance of asphalt pavement.

(1) According to the Marshall test results, the optimal fiber content and the optimal asphalt-stone ratio for SMA-II-1 were $0.18 \%$ and $6.6 \%$, respectively. The optimal fiber content and the optimal asphalt-stone ratio for SMA-II-2 were $0.27 \%$ and $8.1 \%$, respectively. The optimal fiber content and the optimal asphalt-stone ratio for SMA-II-3 were $0.21 \%$ and $7.1 \%$, respectively. In the study of the key controlling indices of mix proportion, the passing rate of the 1.18-mm sieve had a more remarkable influence on the air void content of the mixture than the passing rate of $0.075-\mathrm{mm}$ sieve. The recommended range of the filler-asphalt ratio should be between $1.1 \%$ and $1.4 \%$. The results above can be used as guidance for the mix design of asphalt mixture.

(2) Overall performances of SMA-II-1, SMA-II-2, SMA-II-3 can satisfy requirements of the Chinese specifications according to the high temperature test, the water stability test and the skid resistance test. The beam bend test and the bending strain energy density function were adopted to evaluate the low temperature performance of three kinds of mixtures. Test results show that SMA-II with high rubberized asphalt content has better adaptability for deformation and greater bending strain energy density than traditional SMA-I (SBS-modified mixture), which can demonstrate good crack resistance performance of SMA-II. Life-cycle cost analysis showed the better life-cycle economic benefit of the SPS asphalt mixture thin overlay compared with the traditional AC-13 thin overlay.

(3) The pavement performance of this SPS asphalt mixture needs to be further investigated in engineering practice. In fact, the design method for the material composition and thickness of the asphalt thin overlay still need improvement and innovation in theory, method and practice.

Author Contributions: Conceptualization, J.P., J.Z. and R.L.; Methodology, J.P., J.X. and L.S.; Software, J.X., L.S.; Validation J.X. and L.S.; Formal Analysis, R.L., L.S. and J.X.; Investigation, J.X. and L.S.; Resources, L.S. and J.X.; Data Curation, J.Z., L.S. and J.X.; Writing-Original Draft Preparation, J.X. and L.S.; Writing-Review \& Editing, M.A., J.X.; Visualization, J.X.; Supervision, J.P.; Project Administration, J.P.; Funding Acquisition, J.P.

Acknowledgments: The research was funded by the National Natural Science Foundation of China grant number 51378073 and 51408048, the Key Program for Science and Technology Projects of Shaanxi province grant number 2016ZDJC-24, the China Postdoctoral Science Special Foundation grant number 2016T90880, and the Science and Technology Project of Shaanxi Provincial Communications Department grant number 15-35T. The authors also appreciate the support of China Scholarship Council (CSC) during the research at Waseda University. And the APC was funded by Basic Scientific Research of Central College of Chang'an University grant number 300102219308 and 300102219316.

Conflicts of Interest: The authors declare no conflict of interest.

\section{Appendix A. Technical Indicators of Aggregates and Mineral Filler}

The aggregates and filler used in this study are limestones which were produced in Xi'an City, Shaanxi Province. The technical indicators were shown in Tables A1-A3. 
Table A1. Technical indicators of coarse aggregate.

\begin{tabular}{|c|c|c|c|}
\hline \multicolumn{2}{|c|}{ Indicators } & Unit & Test Result \\
\hline \multicolumn{2}{|c|}{ Crushing value } & $\%$ & 17.3 \\
\hline \multicolumn{2}{|c|}{ LA abrasion value } & $\%$ & 15.6 \\
\hline \multirow{3}{*}{ Bulk density } & $4.75 \mathrm{~mm}$ & \multirow{3}{*}{$\mathrm{g} / \mathrm{cm}^{3}$} & 2.722 \\
\hline & $2.36 \mathrm{~mm}$ & & 2.741 \\
\hline & $1.18 \mathrm{~mm}$ & & 2.727 \\
\hline \multicolumn{2}{|c|}{ Water absorption } & $\%$ & 0.63 \\
\hline \multicolumn{2}{|c|}{ Mud content } & $\%$ & 0.87 \\
\hline \multicolumn{2}{|c|}{ Flakiness index } & $\%$ & 10.1 \\
\hline
\end{tabular}

Table A2. Technical indicators of fine aggregate.

\begin{tabular}{ccc}
\hline Indicators & Unit & Test Result \\
\hline Apparent density & $\mathrm{g} / \mathrm{cm}^{3}$ & 2.717 \\
Mud content & $\%$ & 1.2 \\
Sand equivalent & $\%$ & 57 \\
Methylene blue value & $\mathrm{g} / \mathrm{kg}$ & 19 \\
Angularity & $\mathrm{s}$ & 18.87 \\
\hline
\end{tabular}

Table A3. Technical indicators of mineral filler.

\begin{tabular}{cccc}
\hline Indicators & Test Result & Requirement \\
\hline Apparent density $\left(\mathrm{t} / \mathrm{m}^{3}\right)$ & 2.788 & $\geq 2.5$ \\
\hline Water content $(\%)$ & 0.6 & $\leq 1$ \\
\hline \multirow{3}{*}{ Particle gradation/\% } & $<0.6 \mathrm{~mm}$ & 99.3 & 100 \\
\cline { 2 - 4 } & $<0.15 \mathrm{~mm}$ & 92.1 & $90 \sim 100$ \\
\cline { 2 - 4 } & $<0.075 \mathrm{~mm}$ & 75.4 & $70 \sim 100$ \\
\hline Hydrophilic coefficient & 0.45 & $<1$ \\
\hline \multicolumn{2}{c}{ Plasticity index $(\%)$} & 2.2 & $<4$ \\
\hline
\end{tabular}

\section{Appendix B. Test Methods of Asphalt Mixture}

1. Rutting test

Dynamic stability (DS) could be calculated according to Equation (A1).

$$
\mathrm{DS}=\frac{\left(t_{2}-t_{1}\right) \times N}{d_{2}-d_{1}} \times C_{1} \times C_{2}
$$

where: DS is the dynamic stability of test specimen (times/mm); $t_{1}$ and $t_{2}$ are test time (minute); $d_{1}$ and $d_{2}$ are rutting depth at $t_{1}(\mathrm{~mm})$ and $t_{2}(\mathrm{~mm}) ; C_{1}$ is the correction factor of the wheel tracking apparatus, and its value is 1.0 in this test; $C_{2}$ is the coefficient of compacted specimen, and its value is 1.0 for $300 \mathrm{~mm}$ width specimen; $N$ is wheel speed, 42 times/min in this test.

2. Vacuum saturated Marshall stability test:

Original splitting strength $\left(R_{\mathrm{T} 1}\right)$ and freeze-thaw splitting strength $\left(R_{\mathrm{T} 2}\right)$ were calculated as Equations (A2) and (A3):

$$
\begin{aligned}
& R_{\mathrm{T} 1}=0.006287 P_{\mathrm{T} 1} / h_{1} \\
& R_{\mathrm{T} 2}=0.006287 P_{\mathrm{T} 2} / h_{2}
\end{aligned}
$$


where: $R_{\mathrm{T} 1}$ (Original splitting strength) is the splitting tensile strength of first set of individual specimen without freeze-thaw cycles ( $\mathrm{MPa}$ ); $R_{\mathrm{T} 2}$ (freeze-thaw splitting strength) is the splitting tensile strength of second set of individual specimen subjected to freeze-thaw cycles (MPa); $P_{\mathrm{T} 1}$ is the test load values of first set of individual specimen $(\mathrm{N}) ; P_{\mathrm{T} 2}$ is the test load values of second set of individual specimen $(\mathrm{N}) ; h_{1}$ is the height of first set of individual specimen (mm); $h_{2}$ is the height of second set of individual specimen (mm). Tensile strength ratio (TSR) was calculated based on Equation (A4):

$$
\mathrm{TSR}=\frac{\bar{R}_{\mathrm{T} 2}}{\bar{R}_{\mathrm{T} 1}} \times 100
$$

where: TSR is tensile strength ratio (\%); $\bar{R}_{\mathrm{T} 2}$ is the mean value of splitting tensile strength of second set of effective specimens subjected to freeze-thaw cycles (MPa); $\bar{R}_{\mathrm{T} 1}$ is the mean value of splitting tensile strength of first set of effective specimens without freeze thaw cycles (MPa).

3. Freeze-thaw splitting test:

Residual stability of vacuum saturated Marshall stability test was calculated based on Equation (A5):

$$
\mathrm{MS}_{0}^{\prime}=\frac{\mathrm{MS}_{2}}{\mathrm{MS}} \times 100
$$

where: $\mathrm{MS}_{0}^{\prime}$ is the residual stability (\%) of specimen; $\mathrm{MS}_{2}$ is the stability of vacuum saturated specimen after immersed in water for $48 \mathrm{~h}(\mathrm{kN})$; $\mathrm{MS}$ is the stability of specimen $(\mathrm{kN})$.

4. Low-temperature bend test:

Flexural tensile strength, ultimate tensile strain and bending stiffness modulus were calculated based on Equations (A6)-(A8).

$$
\begin{gathered}
R_{\mathrm{B}}=\frac{3 \times L \times P_{B}}{2 \times b \times h^{2}} \\
\varepsilon_{\mathrm{B}}=\frac{6 \times h \times d}{L^{2}} \\
S_{\mathrm{B}}=\frac{R_{B}}{\varepsilon_{\mathrm{B}}}
\end{gathered}
$$

where: $R_{\mathrm{B}}$ is flexural tensile strength when the test specimen failed (MPa); $\varepsilon_{\mathrm{B}}$ is ultimate tensile strain when the test specimen failed $(\mu \varepsilon) ; S_{\mathrm{B}}$ is bending stiffness modulus when the test specimen failed (MPa); $b$ is the width of test specimen $(\mathrm{mm}) ; h$ is the height of test specimen $(\mathrm{mm}) ; L$ is the span of test specimen (mm); $P_{B}$ is the maximum load when the specimen failed $(\mathrm{N}) ; d$ is the bending of test specimen in the middle of the span (mm).

5. Skid resistance test (Sand patch method):

The texture depth of asphalt mixture was calculated based on Equation (A9), accurate to $0.01 \mathrm{~mm}$.

$$
\mathrm{TD}=\frac{100 \times V}{\pi \times D^{2} / 4}=\frac{31831}{D^{2}}
$$

where: TD is the texture depth of asphalt mixture (mm); V is the volume of sand, $25 \mathrm{~cm}^{3}$; $D$ is the average diameter of sand patch $(\mathrm{mm})$. 


\section{References}

1. Roque, R.; Birgisson, B.; Sangpetngam, B.; Zhang, Z. Hot mix asphalt fracture mechanics: A fundamental crack growth law for asphalt mixtures. J. Assoc. Asph. Paving Technol. 2002, 71, 816-827.

2. Raposeiras, A.C.; Vega-Zamanillo, Á.; Calzada-Pérez, M.Á.; Castro-Fresno, D. Influence of surface macro-texture and binder dosage on the adhesion between bituminous pavement layers. Constr. Build. Mater. 2012, 28, 187-192. [CrossRef]

3. Zhang, J.; Liu, G.; Hu, Z.; Zhu, C.; Pei, J.; Jin, L. Effects of temperature and loading frequency on asphalt and filler interaction ability. Constr. Build. Mater. 2016, 124, 1028-1037. [CrossRef]

4. Brosseaud, Y.; Bellanger, J.; Gourdon, J. Thinner and thinner asphalt layers for the maintenance of French roads. Transp. Res. Record. 1992, 1334, 9-11.

5. Cao, W.D.; Shen, J.R.; Han, H.C. Introduction of Technology of Ultra-Thin Asphalt Friction Course. Petroleum Asphalt. 2005, 19, 56-58. [CrossRef]

6. Uhlmeyer, J.S.; Pierce, L.M.; Weston, J.T. Novachip ${ }^{\circledR}$. Post Construction/Performance Report, Experimental Feature WA01-01; Washington DOT: Olympia, WA, USA, 2003.

7. Zuo, Q.Y. Research on Application Technology of Thin Overlay with LASTIKA Asphalt Concrete. Master's Thesis, Changsha University of Science \& Technology, Changsha, China, 2007.

8. Carswell, J. The design and performance of thin surfacing layers. In Proceedings of the 12th AAPA International Flexible Pavements Conference, Melbourne, Victoria, Australia, 5-8 October 2003.

9. Dantas-Neto, S.A.; Farias, M.M.; Pais, J.C.; Pereira, P.A. Dense graded hot mixes using asphalt-rubber binders with high rubber contents. Road Mater. Pavement Des. 2006, 7, 29-46. [CrossRef]

10. Li, R.; Li, Y.; Shi, X.; Du, Q.; Wen, Y.; Pei, J. Study on design method and pavement performance of asphalt mixtures for thin layer overlay. J. China Foreign Highw. 2012, 32, 263-266. [CrossRef]

11. Ahammed, M.A.; Tighe, S.L. Asphalt pavements surface texture and skid resistance-Exploring the reality. Can. J. Civ. Eng. 2011, 39, 1-9. [CrossRef]

12. Shao, L.B. Research on Design Method of Material Composition for Small Grain Size Asphalt Mixtures Based on Practical Function. Master's Thesis, Chang'an University, Xi'an, China, 2011.

13. Li, R.; Li, Y.; Shi, X.; Liu, Z.; Yang, J.; Pei, J. Design of small stone asphalt mixture based on anti-skidding performance. J. Wuhan Univ. Technol. Mater. Sci. Ed. 2012, 27, 789-793. [CrossRef]

14. Chen, D.H.; Scullion, T. Very Thin Overlays in Texas. Constr. Build. Mater. 2015, 95, 108-116. [CrossRef]

15. Son, S.; Al-Qadi, I.L.; Zehr, T. 4.75 mm SMA Performance and Cost-Effectiveness for Asphalt Thin Overlays. Int. J. Pavement Eng. 2016, 17, 799-809. [CrossRef]

16. Wang, X.-C.; Liu, K.; Li, S.-Q. Study on resistance to reflective crack of interlayer materials in asphalt overlay. J. Build. Mater. 2010, 13. [CrossRef]

17. Fallah, S.; Khodaii, A. Reinforcing overlay to reduce reflection cracking; an experimental investigation. Geotext. Geomembr. 2015, 43, 216-227. [CrossRef]

18. Kumar, V.V.; Saride, S. Evaluation of cracking resistance potential of geosynthetic reinforced asphalt overlays using direct tensile strength test. Constr. Build. Mater. 2018, 162, 37-47. [CrossRef]

19. Zhang, J.; Tan, H.; Pei, J.; Qu, T.; Liu, W. Evaluating Crack Resistance of Asphalt Mixture Based on Essential Fracture Energy and Fracture Toughness. Int. J. Geomech. 2019, 19, 06019005. [CrossRef]

20. Liu, H.; Hao, P.; Xu, J. Effects of nominal maximum aggregate size on the performance of stone matrix asphalt. Appl. Sci. 2017, 7, 126. [CrossRef]

21. Garcia-Gil, L.; Miró, R.; Pérez-Jiménez, F. Evaluating the Role of Aggregate Gradation on Cracking Performance of Asphalt Concrete for Thin Overlays. Appl. Sci. 2019, 9, 628. [CrossRef]

22. Sun, L.; Wang, G.; Zhang, H.; Liu, L. Initiation and Propagation of Top-Down Cracking in Asphalt Pavment. Appl. Sci. 2018, 8, 774. [CrossRef]

23. Shi, K.L. Research on Preventing Reflection Cracks of Asphalt Pavement with High Viscous Asphalt Stress Absorbing Layer. Master's Thesis, Harbin Institute of Technology, Harbin, China, 2006.

24. Heitzman, M.A. State of the Practice: Design and Construction of Asphalt Paving Materials with Crumb-Rubber Modifier; Final Report (No. PB-92-203900/XAB; FHWA/SA-92/022); Office of Engineering, Federal Highway Administration: Washington, DC, USA, 1992. 
25. Xiaoming, H.; Eldouma, I.B. Experimental Study to Determine the Most Preferred Additive for Improving Asphalt Performance Using Polypropylene, Crumb Rubber, and Tafpack Super in Medium and High-Temperature Range. Appl. Sci. 2019, 9, 1567. [CrossRef]

26. Palit, S.K.; Reddy, K.S.; Pandey, B.B. Laboratory evaluation of crumb rubber modified asphalt mixes. J. Mater. Civ. Eng. 2004, 16, 45-53. [CrossRef]

27. Mozaffari, S.; Tchoukov, P.; Atias, J.; Czarnecki, J.; Nazemifard, N. Effect of asphaltene aggregation on rheological properties of diluted Athabasca bitumen. Energy Fuels 2015, 29, 5595-5599. [CrossRef]

28. Mozaffari, S.; Tchoukov, P.; Mozaffari, A.; Atias, J.; Czarnecki, J.; Nazemifard, N. Capillary driven flow in nanochannels-Application to heavy oil rheology studies. Colloids Surf. A Physicochem. Eng. Asp. 2017, 513, 178-187. [CrossRef]

29. Dong, C.C. Comprehensive Utilization of Waste Rubber Resources; Chemical Industry Press: Beijing, China, 2003; ISBN 9787502546236.

30. Szerb, E.I.; Nicotera, I.; Teltayev, B.; Vaiana, R.; Rossi, C.O. Highly stable surfactant-crumb rubber-modified bitumen: NMR and rheological investigation. Road Mater. Pavement Des. 2018, 19, 1192-1202. [CrossRef]

31. China Ministry of Transport. JT/T 798-2011 Asphalt Rubber for Highway Engineering; China Communications Press: Beijing, China, 2011.

32. China Ministry of Transport. JTG E20-2011 Specifications and Test Methods of Bitumen and Bituminous Mixtures for Highway Engineering; China Communications Press: Beijing, China, 2011.

33. Sheng, Y.; Li, H.; Guo, P.; Zhao, G.; Chen, H.; Xiong, R. Effect of Fibers on Mixture Design of Stone Matrix Asphalt. Appl. Sci. 2017, 7, 297. [CrossRef]

34. Wu, S.; Ye, Q.; Li, N. Investigation of rheological and fatigue properties of asphalt mixtures containing polyester fibers. Constr. Build. Mater. 2008, 22, 2111-2115. [CrossRef]

35. Lira, B.; Jelagin, D.; Birgisson, B. Gradation-based framework for asphalt mixture. Mater. Struct. 2013, 46, 1401-1414. [CrossRef]

36. Harman, T.; D’Angelo, J.; Bukowski, J. Superpave Asphalt Mixture Design Workshop Workbook; US Department of Transportation, Federal Highway Administration: Washington, DC, USA, 2002.

37. Chen, A.W.; Hao, P.W. Design and Test of Gradation by Bailey Method. J. China Foreign Highw. 2004, 5, 101-103. [CrossRef]

38. Chen, Z.D.; Yuan, W.J.; Zheng, D.Q. Study on the application of grading theory. J. Chongqing Jiaotong Univ. 2005, 24, 44-48. [CrossRef]

39. China Ministry of Transport. JTG F40-2004 Technical Specification for Construction of Highway Asphalt Pavements; China Communications Press: Beijing, China, 2004.

40. Wang, J.; Gong, Y.F. Influence of filler-bitumen ratio on asphalt combined binder and mixture performance. J. Changsha Commun. Univ. 2004, 20, 73-77. [CrossRef]

41. China Ministry of Transport. JTG E60-2008 Field Test Methods of Subgrade and Pavement for Highway Engineering; China Communications Press: Beijing, China, 2008.

42. Jia, G. Analysis and Evaluation of Low Temperature Performance Test of SBS Modified Asphalt mixtures. Highw. Automot. Appl. 2008, 1, 83-85. [CrossRef]

43. Babashamsi, P.; Yusoff, N.I.M.; Ceylan, H.; Nor, N.G.M.; Jenatabadi, H.S. Evaluation of pavement life cycle cost analysis: Review and analysis. Int. J. Pavement Res. Technol. 2016, 9, 241-254. [CrossRef]

(C) 2019 by the authors. Licensee MDPI, Basel, Switzerland. This article is an open access article distributed under the terms and conditions of the Creative Commons Attribution (CC BY) license (http://creativecommons.org/licenses/by/4.0/). 